\title{
Feeding With Various Microalgae The Salt "Loving" Ciliate Fabrea Salina in Normal Salinity of 35 ppt
}

\author{
George N. Hotos \\ How to cite this paper: Hotos G N.. (2019) \\ Feeding With Various Microalgae The Salt \\ "Loving" Ciliate Fabrea Salina in Normal \\ Salinity of 35 ppt. International Journal of \\ Food Science and Agriculture, 3(3), 150-152.
}

Plankton Culture Laboratory, Department of Animal Production, Fisheries and Aquaculture, University of Patras, Greece.
DOI: 10.26855/ijfsa.2019.09.001

*Corresponding author: George N. Hotos, Plankton Culture Laboratory, Department of Animal Production, Fisheries and Aquaculture, University of Patras, Greece.

Email: ghotos@upatras.gr

\begin{abstract}
In a laboratory study 6 microalgae species were tested as food for the extremely halotolerant ciliate Fabrea salina in salinity of 35 ppt. Rhodomonas salina was found to be the best food in terms of specific growth rate and generation time followed by Dunaliella salina and Asteromonas gracilis. Isochrysis galbana, Chlorella sp and Tetraselmis sp were found inferior to them. In order to get best results in $35 \mathrm{ppt}$, Fabrea salina should previously be acclimatized in salinities as low as $60 \mathrm{ppt}$ at least (as compared to $90 \mathrm{ppt}$ that is quite near to the salinities of above $100 \mathrm{ppt}$ that are normal in the hypersaline ponds from where Fabrea is collected).
\end{abstract}

\section{Keywords}

microalgae, salinity, ciliate

\section{Introduction}

In the hypersaline ponds the dominant ciliate protozoan is the heterotrichous species Fabrea salina Henneguy (1989) (Fig. 1) that can withstand very high salinities due to its osmoadaptation physiological mechanisms. Its size varies greatly ( 80 $-350 \mu \mathrm{m}$ ) for reasons not clarified yet, but in average can be considered as equivalent to that of the rotifer Brachionus plicatilis that is the undisputable first live feed used in marine hatcheries.

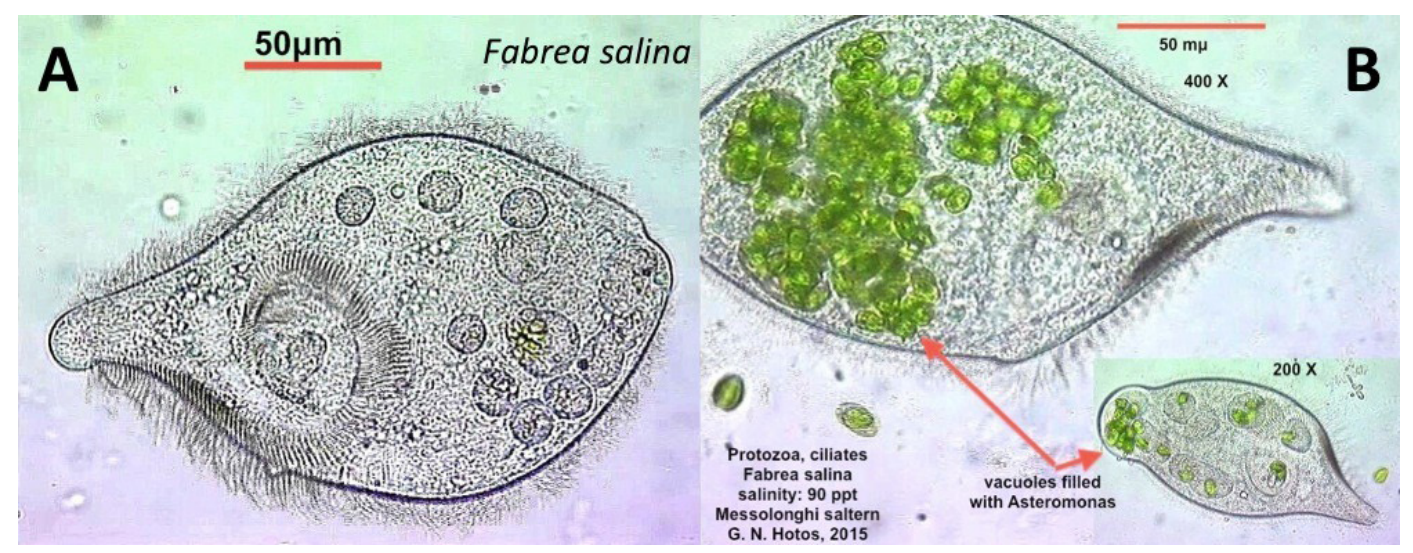

Figure 1. The ciliate Fabrea salina. A: with empty vacuoles. B: with vacuoles full of the microalga Asteromonas gracilis.

Any organism to serve as a novel live food candidate is welcomed in order to enrich the catalogue of alternative options in regard to the dominance of rotifers. Although protozoans have been indicated as food sources in fish larviculture [1], very few of them have been grown in monocultures. F. salina satisfies the majority of criteria attributed to a microscopic organism that is to be used as live food. Small size, strictly pelagic nature, short generation time, filter feeder, cyst formation, short generation period and euryplasticity make it a promising species for feeding larval marine fish and 
shellfish. Strange as it may be, till today there are only scarce reports of experimental trials of feeding larvae with this ciliate [2]. The majority of the available limited information concerns its culture in vitro using various particulate foods and conditions. Even so, the exploitation of its potential for mass culture is continued. One drawback that has to be overcome is to effectively culture this ciliate in salinities comparable to the salinity larval fish are kept. That is somewhere in the region of 30-40 ppt. F. salina thrives at salinities over 80 ppt so it is absolutely necessary to ensure that it can be effectively cultured in salinities much lower $(\sim 35 \mathrm{ppt})$ in order to facilitate its good health when offered to the larvae. The purpose of the present study is exactly this. To test the adaptability of $F$. salina in water of 35 ppt without loss of viability and ability of feeding on microalgae.

\section{Materials and Methods}

A sample of Fabrea salina collected from a Messolonghi saltworks pond with a salinity of 123 ppt was kept in the laboratory fed with the halotolerant microalgae Asteromonas gracilis and Dunaliella salina that were also isolated from the saltworks. The salinity was gradually brought to $90 \mathrm{ppt}$ and $F$. salina kept there in a $1 \mathrm{~L}$ conical flask for 15 days fed a mixture of the above microalgae with an average density of $8 \times 10^{4}$ cells $/ \mathrm{ml}$ and Fabrea attained a final density of $90 \mathrm{ind} / \mathrm{ml}$. Illumination kept constant at 1000 lux at the surface of the vessel. In parallel, another 1L flask was used to acclimatize Fabrea at 60 ppt salinity for 15 days with the same food and illumination as above and finally Fabrea attained a final density of $85 \mathrm{ind} / \mathrm{ml}$.

From the depository $1 \mathrm{~L}$ vessels of 90 and $60 \mathrm{ppt}$ an appropriate number of Fabrea was taken and introduced in 250 $\mathrm{ml}$ Erlenmeyer flasks filled with $200 \mathrm{ml}$ of $35 \mathrm{ppt}$ filtered seawater in such a way as to achieve an initial density of 1 Fabrea/ml (1 ind/ml). The cilates were fed with the microalgae: Rhodomonas salina, Isochrysis galbana, Tetraselmis sp., Dunaliella salina, Asteromonas gracilis and Chlorella sp. Each culture was conducted in triplicates and kept without aeration at room temperature of $20^{\circ} \mathrm{C}$ and 1000 lux illumination.

The procedure comprised of two successive steps (experiments). The first experiment used Fabrea previously acclimatized at $60 \mathrm{ppt}$ and fed with the following microalgae which were introduced in paste mass as to give the indicated initial densities: Asteromonas $\left(2 \times 10^{5}\right.$ cells $\left./ \mathrm{ml}\right)$, Dunaliella $\left(1 \times 10^{5}\right.$ cells $\left./ \mathrm{ml}\right)$, Tetraselmis $\left(2 \times 10^{5}\right.$ cells $\left./ \mathrm{ml}\right)$, Chlorella $\left(2 \times 10^{6}\right.$ cells $\left./ \mathrm{ml}\right)$, Isochrysis $\left(3 \times 10^{5}\right.$ cells $\left./ \mathrm{ml}\right)$ and Rhodomonas $\left(2 \times 10^{5}\right.$ cells $\left./ \mathrm{ml}\right)$. A total of $18,250 \mathrm{ml}$ flasks were used ( 3 flasks per each of the 6 microalgae used). In the second experiment Fabrea previously acclimatized at 90 ppt were fed (with similar algal densities) with the 3 microalgae that gave the best results in the first experiment. A total of 9, $250 \mathrm{ml}$ flasks were used ( 3 flasks per each of the 3 microalgae used). The total production of $F$. salina, its growth rate and generation time were recorded for each microalgae in each experiment. Statistical analysis used ANOVAKruskal-Wallis comparisons at 0,05 level of significance.

\section{Results and Discussion}
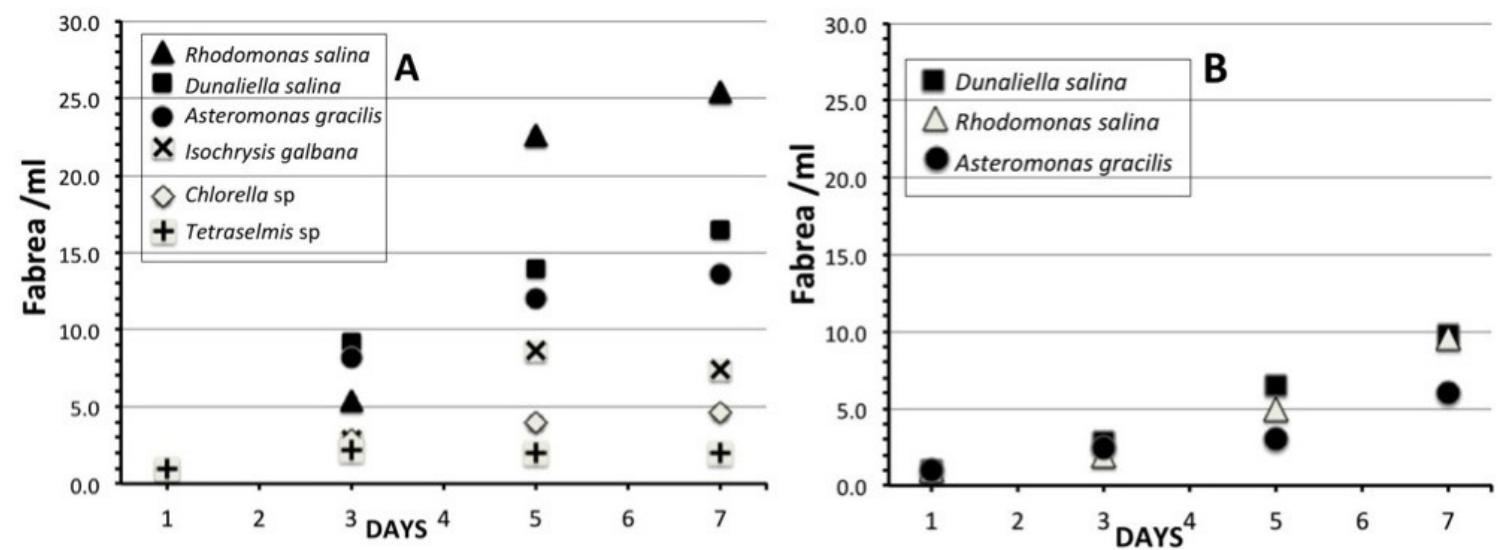

Figure 2. The densities of Fabrea salina attained in cultures of 35 ppt salinitiy using different microalgal foods. In A: Fabrea was previously acclimatized to $60 \mathrm{ppt}$, while in B: was acclimatized to $90 \mathrm{ppt}$. 
The results of the first experiment (Fig. 2-A) using Fabrea previously adapted in 60 ppt, exhibited two groups of microalgae in terms of their effectiveness in the increase of Fabrea population. Rhodomonas, Dunaliella and Asteromonas gave after 7 days an average of 25,4, 16,6 and 13,6 Fabrea/ml respectively. These results are significantly higher $(\mathrm{p}<0,05)$ from those attained by using Isochrysis, Chlorella and Tetraselmis $(7,4$, 4,6 and 2 Fabrea/ml respectively). It is logical to assume that the halotolerant algae Dunaliella and Asteromonas are best suited as food for Fabrea, because these species comprise much of its natural food in the hypersaline natural environment. But the most impressive finding was that Rhodomonas a species not reported (so far) to cope well in elevated salinities, gave ( $<<0,05$ ) the best growth in Fabrea even at the moderate salinity of 35 ppt that can be generally considered as too low for Fabrea too high for Rhodomonas.

In the second experiment (Fig. 2-B) using Fabrea previously adapted to $90 \mathrm{ppt}$ and Rhodomonas, Dunaliella and Asteromonas as food, the 7 days maximum densities of Fabrea (9,5, 9,8 and 6 Fabrea/ml) were similar (p $>0.05)$ among the microalgae used (Rhodomonas, Dunaliella and Asteromonas respectively). The lower values of Fabrea's densities of this experiment as compared $(\mathrm{p}<0.05)$ to the first experiment are probably attributable to the more stressful procedure for the ciliate as it was transferred from a very high salinity of $90 \mathrm{ppt}$ to $35 \mathrm{ppt}$ compared to the smaller salinity difference (from $60 \mathrm{ppt}$ to $35 \mathrm{ppt}$ ) of the first experiment. It seems that its osmoregulation mechanism needs more time to adapt to lower salinities than to higher ones (personal observations, unpublished data) and the more abrupt the salinity change (from higher to lower) the more time it takes to resume normal metabolism.

In terms of specific growth rate and generation time (Table 1) the values for the most effective microalgae are considered quite high $\left(\mathrm{R}=0,37-0,46, \mathrm{~T}_{\mathrm{g}}=1,50-1,87\right.$ days) compared to those of Guermazi et al [3] $(\mathrm{R}: 0,23-0,30$ for Isochrysis and Dunaliella respectively).

In conclusion, F. salina can be cultured in normal sea-water effectively accepting unicellular algal feeds and future research should focus on optimizing conditions and manipulations of microalgal feeds in order to maximize yields.

Table 1. Specific growth rate $(\mathrm{R})$ and generation time $\left(\mathrm{T}_{\mathrm{g}}\right)$ of Fabrea salina fed different microalgae (same or different superscripts are indicative of statistically similar or different values respectively at the 0,05 level).

\begin{tabular}{|l|l|l|l|l|l|}
\hline Fabrea salina from 60 to 35 ppt & $\mathbf{R}$ & $\mathbf{T}_{\mathbf{g}}$ & Fabrea salina from 90 to 35 ppt & $\mathbf{R}$ & $\mathbf{T}_{\mathbf{g}}$ \\
\hline Rhodomonas & $0,46^{*}$ & 1,50 & Rhodomonas & $0,32^{@}$ & 2,16 \\
\hline Dunaliella & $0,40^{+}$ & 1,70 & Dunaliella & $0,32^{@}$ & 2,16 \\
\hline Asteromonas & $0,37^{+}$ & 1,87 & Asteromonas & $0,25^{-}$ & 2,77 \\
\hline Isochrysis & $0,28^{-}$ & 2,47 & & & \\
\hline Chlorella & $0,21^{-}$ & 3,30 & & & \\
\hline Tetraselmis & $0,10^{\#}$ & 6,90 & & & \\
\hline
\end{tabular}

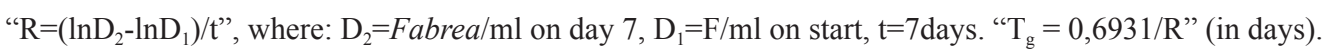

\section{References}

[1] Das, P., Mandai, S. C., Bhagabati, S. K., Akhtar, M. S. and S. K. Singh (2012). Important live food organisms and their role in aquaculture. Frontiers in Aquaculture, 69-86. Narendra Publ. House.

[2] Rhodes, A. M. \& R. P. Phelps (2006). Ciliated protozoans as alternative live food for first feeding red snapper, Lutjanus camperchanus, larvae. GCFI:57, 57 ${ }^{\text {th }}$ Gulf and Caribbean Fisheries Institute, pp. 963-973.

[3] Guermazi, W., Elloumi, J., Ayadi, H., Bouain, A. \& L. Aleya (2008). Rearing of Fabrea salina Henneguy (Ciliophora, Heterotrichida) with three unicellular feeds. C. R. Biologies 331, Elsevier, 56-65. doi:10.1016/j.crvi.2007.10.006. 